\title{
Post-Tsunami Lifeline Restoration and Reconstruction
}

\author{
Yasuko Kuwata \\ Kobe University, \\ Japan
}

\section{Introduction}

The 2004 Indian Ocean earthquake and tsunami caused severe damage to houses and infrastructure and resulted in massive human casualties in several countries. Although there have been several reports on the resulting damage to lifelines, processes for the restoration and reconstruction of the lifelines have not been reviewed well; these processes are important in view of the effects on people's life, the community, and industrial conditions. A lifeline refers to a vital infrastructure in our lives. As a city becomes modernized and its population increases, a lifeline service covers a larger area with a complicated network system. After the 2004 tsunami, it took as long as a few weeks, and sometimes several months, before the process of restoration and reconstruction was begun. The victims of the tsunami faced many problems that differed from those that occur after an earthquake. This chapter attempts to elucidate the post-tsunami lifeline restoration and reconstruction process from several points of view by using case studies from Indonesia, Thailand, and Sri Lanka. Tsunami restoration evaluation modeling and its application are discussed. Moreover, methods for town reconstruction planning for lifeline reconstruction are discussed.

Among the lifelines, adequate water supply is important to residential life. Most coastal residential areas, which are at the highest risk from a tsunami, use domestic water from shallow wells. After the 2004 tsunami, worldwide support facilitated the water-supply system to be reconstructed as part of the disaster reconstruction projects, and the residents in the affected areas changed their water-supply system from shallow wells to a pipeline network. The end of this chapter contains an analysis of the lifeline reconstruction and its long-term effects, with the focus on residential awareness of water use before and after the tsunami.

\section{How are lifeline systems damaged by a tsunami wave?}

In a lifeline system, electrical poles and facility buildings can be damaged by a tsunami wave in the same way that houses can be damaged. In the 2004 tsunami, pipelines were also damaged despite the fact that they were installed underground. The mechanism of lifeline damage under the tsunami wave is explained through spatial analysis of the underground pipeline damage and inundation distribution in a case study of southern Thailand. 


\subsection{Water-supply pipeline damage in Nam Kem village}

The coastal area of Phang Nga province, in the southern part of Thailand, mostly uses domestic water from a shallow well. Only Nam Kem village uses water supplied through water-supply pipelines, with the water being drawn from Ta Kua Pa city (inland, east of Nam Kem village). At the time of the 2004 tsunami, the Provincial Water Works Authority [PWWA] of Ta Kua Pa had 2,000 customers, of which 300 resided in Nam Kem village. On the day of the event, the PWWA staffs closed valves on the upstream pipeline because the damage to the downstream pipeline was thought to be considerable. The main pipeline, with a diameter of $200 \mathrm{~mm}$ along the national main roadway, the Petch Kasem road, had no damage, whereas most of the pipelines near the shore were destroyed. Therefore, residents could not use water from the water-supply network. They could also not use water from shallow wells because of the inflow of salt water.

Many parts of the water pipelines were destroyed in the western part of Nam Kem village, as shown in Fig. 1, which illustrates the damaged and intact pipelines in the inundation zones. Whereas the water-supply pipelines located $200 \mathrm{~m}$ from the coastline were completely destroyed by the tsunami, no pipeline damage is seen in regions $500 \mathrm{~m}$ from the coast. The level of damage to houses is also confined to the inundation zone. The people of Nam Kem village were the most severely affected, with 199 killed and 255 missing, after the report of Bang Muang TAO (small district of Phang Nga province).

Pipeline damage was caused by collisions of driftwood and pebbles that were carried by the tsunami wave, as well as ground scouring caused by the tsunami. Coastal embankments and river bridge abutments were scoured, leaving the underground pipeline and surrounding facilities exposed (see Photo 1). There was extensive damage to the water meter because it was positioned above the ground and connected to fragile pipes (see Photo 2).

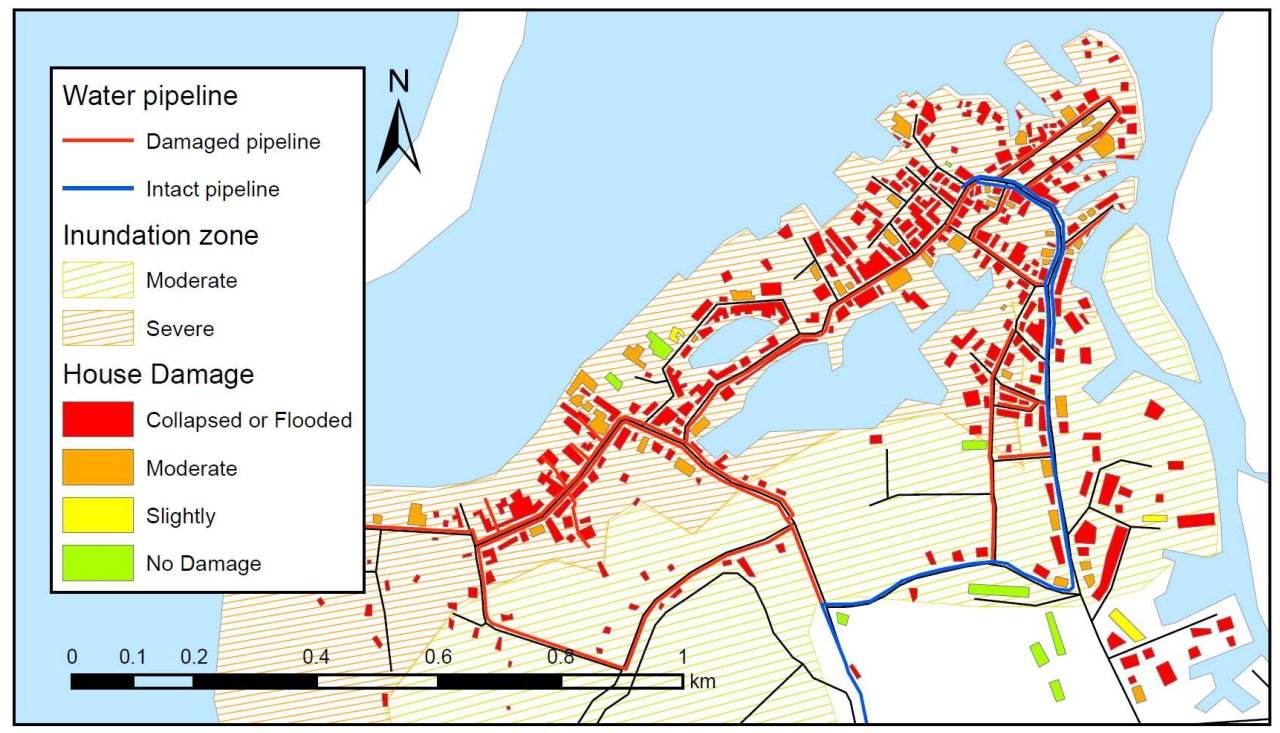

Fig. 1. Pipeline and house damage in Nam Kem village due to the 2004 tsunami. Inundation zones and house damage were taken from damage assessment reports of the local government. Water pipeline information is based on a PWWA report (PWWA, 2007) 
The residential pipe on the customer side of the meter was generally a fragile vinyl pipe (VP), whereas the service pipe on the PWWA side of the meter was a flexible polyethylene pipe (PE). Although the vulnerable water meter sustained severe damage, the repaired meter and piping maintained the previous standards. In addition to the physical damage to the facilities, it is believed that the water-supply facilities were broken by scrapers during the recovery work after the tsunami since the location of the pipeline beneath the ruins could not be identified. Fortunately, the water purification plant was located in the mountains as far as $18 \mathrm{~km}$ from the coast, and it was undamaged.

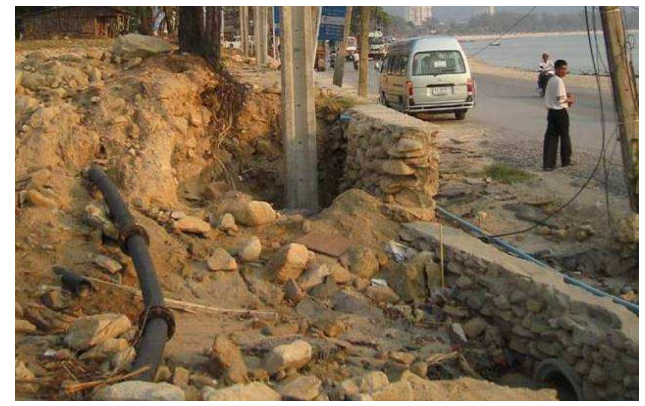

Photo 1. Exposed pipeline after scouring of embankment soil (Phuket, Thailand)

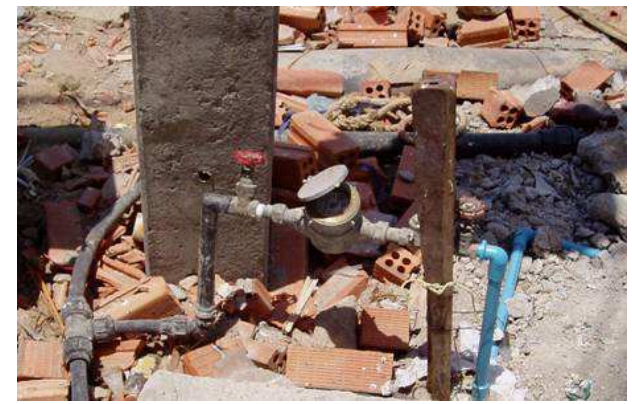

Photo 2. Water meter above ground. Blackcolored polyethylene pipe is the service pipe of PWWA, and the blue-colored vinyl pipe is the residential pipe (Khao Lak, Thailand)

\subsection{Electric power supply network damage}

The electric power supply for the 40,000 customers of Phang Nga province is managed by Provincial Electricity Authority [PEA] of Phang Nga. Out of the eight administrative districts, Khura Buri, Ta Kua Pa, and Thai Mueang sustained severe damage to their electric power facilities. The main facilities, including the aerial electric power line, service transformer, and electric power meter, were damaged. For instance, damaged lengths reached $36 \mathrm{~km}$ for the high voltage line and $28 \mathrm{~km}$ for the low voltage line. As shown in Fig. 2, the high-voltage line ran along the main roadway, the Petch Kasem road, parallel to the coastline. The interruption in the inland low-voltage line was caused by the tsunami striking the high-voltage trunk lines along the coast. The damage rate (damaged aerial electric line length per total line length) was 80 to $100 \%$ in the inundation zone, where the inundation height was estimated to be 6 to $7 \mathrm{~m}$.

The electric power service interruption was caused by the collapse of electric poles because of the tsunami (Thailand witnessed a weak earthquake, so most of the damage was caused by the tsunami). Some poles had cracks at the bottom and others had cracks at the center. The locations of the cracks varied because of the random nature of the colliding driftwood (see Photo 3). The other cause of damage was the scouring of the pole foundations (see Photo 4), which caused the poles to tilt or fall, resulting in the snapping of the power lines. The electric power supply through an underwater cable (400 m length) from Nam Kem village to Kho Khao Island was interrupted because the electric tower on the coast of Nam Kem village was flooded, although the underwater cable itself was not damaged. Similarly, 


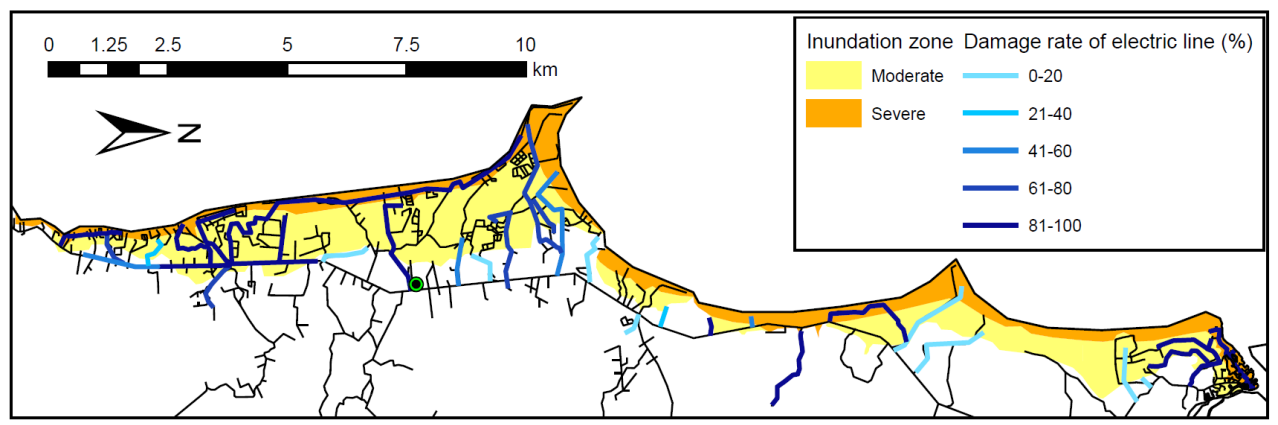

Fig. 2. Inundation zone and electric power line damage in Khao Lak, Thailand. Damage rate is after Provincial Electricity Authority of Phang Nga.

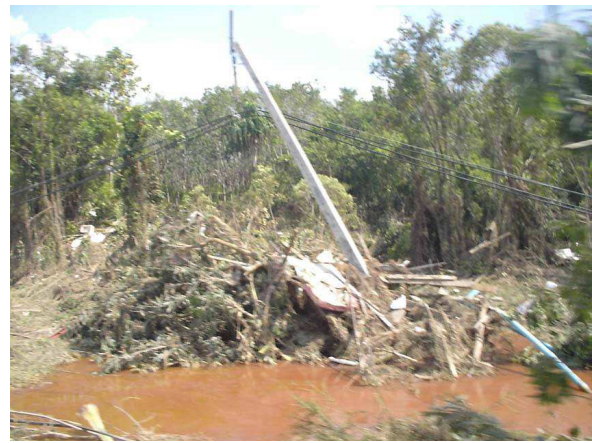

Photo 3. Electric pole tilted by collision with tsunami driftwood (Khao Lak, Thailand)

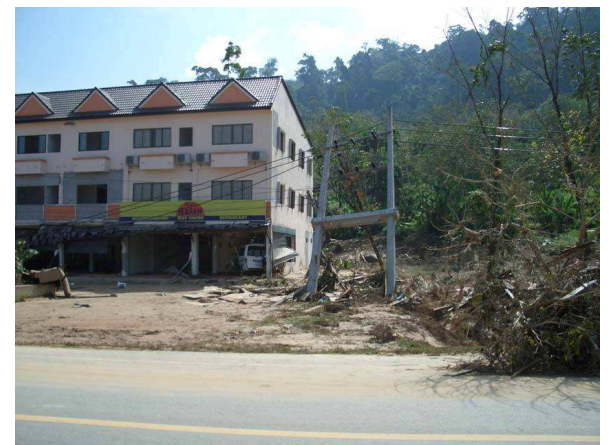

Photo 4. Electric pole tilted as a result of the scouring of the ground by the tsunami (Khao Lak, Thailand)

the underground electric power cable along Karon Beach in Phuket was not damaged. Underground cables seem to fare better in a tsunami. Even so, the underground cable was used only at Karon Beach in Phuket and but in Phang Nga province because of its high cost. Underground cables contribute to the preservation of the landscape in tourist areas, as well as disaster mitigation. Comprehensive regional planning of lifeline infrastructures focusing on land use is expected.

\section{Lifeline-related business recovery}

\subsection{Business continuity management after a tsunami}

Destructive natural disasters such as earthquakes, tsunamis, floods, and typhoons frequently occur all over the world and cause a great deal of property damage and loss of life. Many businesses are also damaged in these disasters. The recovery of business in the affected areas is a big issue for the local societies. Interest in "business continuity management (BCM)" after such disasters has recently been increasing among state governments, local governments, and business organizations. For example, the Cabinet Office of Japan (2005) created a guideline on business continuity. BCM involves the 
preparation of plans, the allocation of resources, and the implementation of processes such that an organization can recover quickly and safely from an interruption (crisis, emergency, event, etc.), with minimum negative impact to people, premises, assets, and operations.

Understanding the process of lifeline restoration and lifeline-related industrial business recovery helps in planning and preparing for future disasters. A method is proposed to evaluate the functionality of a business after a tsunami, with a focus on lifeline function. This method has several modules, including damage estimation of business base (building, equipment, and lifeline) caused by the tsunami, a rate-to-time model to restore the business bases, and the functionality of the business introduced by facility restoration and its influence on the business (Kuwata et al., 2006). ATC-13 (Applied Technology Council, 1985) provided a methodology to evaluate the functionality of a facility, including lifeline effects after an earthquake in California. Referring to ATC-13, the present study proposes a new model of damage estimation and recovery curve for a tsunami. As a case study, the impact of a tsunami on industries and the subsequent restoration process were studied based on an interview survey done in southern Sri Lanka after the 2004 Indian Ocean tsunami, and the survey results were applied to the proposed model.

\subsection{Post-tsunami business recovery in Galle, Sri Lanka}

A survey on tsunami damage to a business base and the restoration process was carried out in Galle, southern Sri Lanka, in late September of 2005, 9 months after the 2004 tsunami. Interview respondents included company owners and other relevant people who have businesses from several industries around the coastal areas. The main industries in Galle are fishing and tourism, and each company is relatively small, with only a few employees (see Photos 5 and 6). The total number of responses in this survey is only 52, because the survey period was limited and the interviews were done face-to-face. The questions were on tsunami inundation levels, physical damages to buildings and equipment and recovery time in days, tsunami damages to lifeline services and recovery time in days, and business restoration processes with respect to the time since the tsunami.

Fig. 3 shows the business recovery process of the local industries, which is the average of responses in each industry, as shown weekly for the first three months and every couple of weeks after that. Here the rate of business recovery is defined as the sales of their products compared to that before the tsunami based on the interview of owners. As is readily seen, lifeline and financial (banking) businesses were recovered remarkably quickly. The reason for the rapid recoveries that office buildings did not have extensive damage and their officers could respond to those damages promptly. They could also receive emergency relief and repair workers from the unaffected offices thanks to mutual cooperation. The reason the banks recovered rapidly is that their main offices are in Colombo, and they served as a backup system for customer information. Communications and relationships in non-crisis times are thus important and effective in cases of emergency.

The recovery of agriculture was relatively quick because the farmers were far from the sea and did not have major damage to their business base. However, it took a long time for the agricultural sectors to be completely restored because it was necessary to purify the soil, which contained saline due to the tsunami. Nine months after the tsunami tourism, manufacturing, and wholesale and retail trade businesses had been slowly recovered to the level of about $60 \%$. In Galle, a large number of collapsed houses remained untouched at the time of the survey, and the local society was still in the process of recovery. Several hotels 
had resumed business, but most visitors were domestic tourists, restoration relief teams, or research groups. Foreign vacationing tourists had not returned as of yet. Some fishermen lost their boats in the tsunami and could not buy new boats. The other fishermen said that they could not sell fish during the few months after the tsunami because the local victims of the tsunami did not want to eat them. The effects of tsunami damage vary depending on the industry, and they go beyond the physical damage to the facilities.

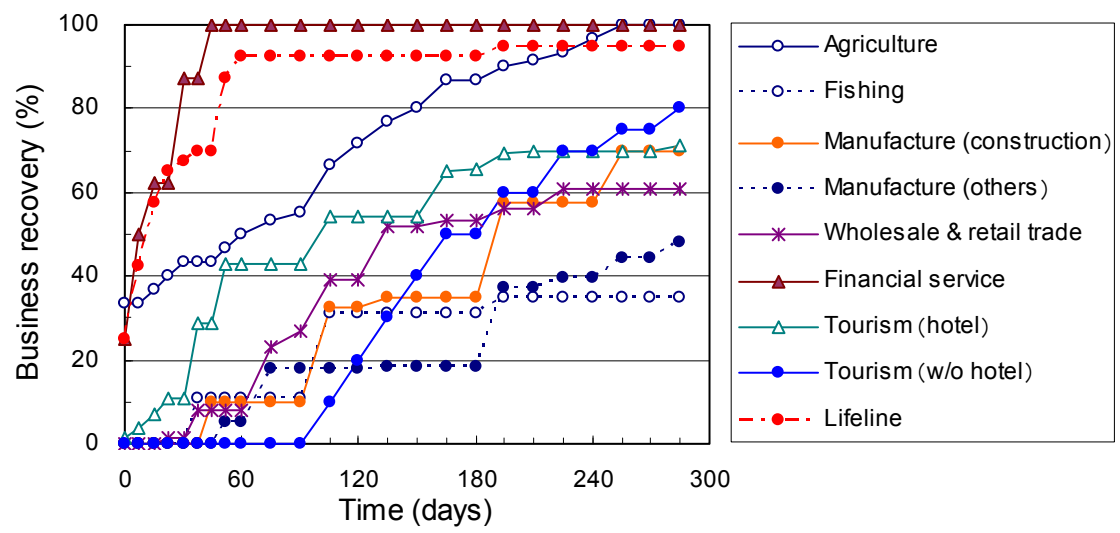

Fig. 3. Business recovery process of industry from tsunami in Sri Lanka

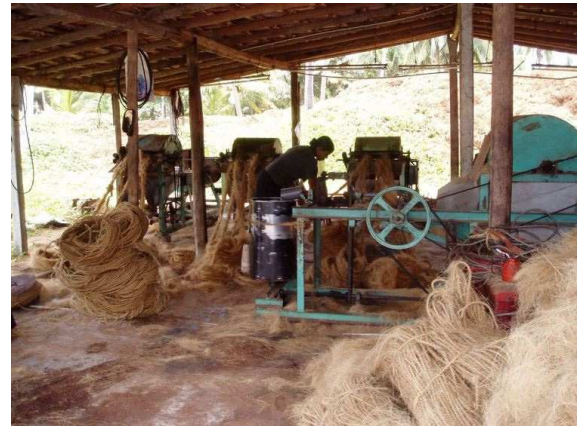

Photo 5. Rope production factory (Galle, Sri Lanka)

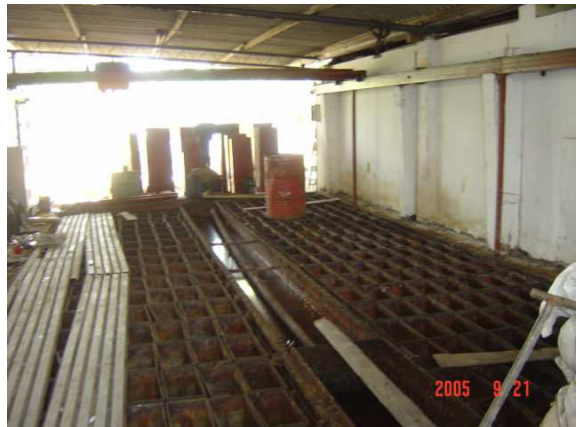

Photo 6. Ice production factory (Galle, Sri Lanka)

\subsection{Post-tsunami business base restoration modeling}

An evaluation method for tsunami damage and the restoration curve of the business base is proposed herein. The business base used in this study involves building, equipment, and lifeline service. Fig. 4 shows the schematic evaluation model, including damage estimation of the business base caused by the tsunami, rate-to-time model for restoration of the business bases, and the business recovery rate resulting from facility restoration and its influence on the business.

The restoration rate is expressed probabilistically by the damage state of a facility and its conditional restoration rate. Business restoration is not determined by the facilities and 
lifeline service because their effects vary depending on the type of business. This model just considers the business basis from a physical point of view. These effects are considered based on the importance factors.

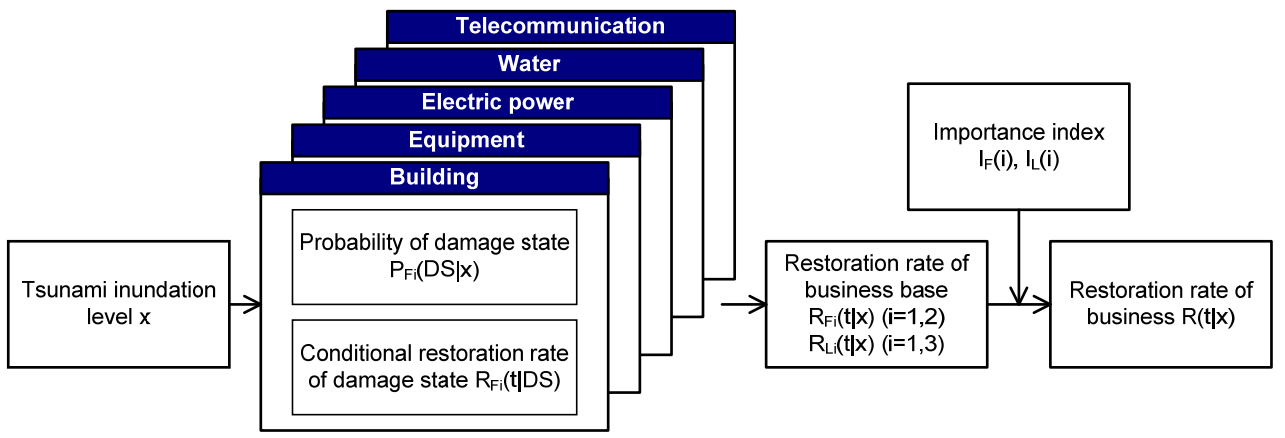

Fig. 4. Business restoration evaluation model after tsunami disaster considering facility and lifeline services

First of all, define the tsunami intensity level. When the hazard is an earthquake, ground motion such as peak ground acceleration and seismic intensity would be an index of intensity level. Shuto (1992) defined tsunami intensity by the square value of the tsunami inundation height and categorized damage based on previous tsunami damage records in terms of its index. This study does not use the tsunami intensity as the square value of inundation height because of the consideration of the limited inundation height in the case study area. The tsunami intensity levels are determined as five discrete levels of inundation height; levels 1 to 5 correspond to no inundation, less than 1,2 , and $3 \mathrm{~m}$, and over $3 \mathrm{~m}$, respectively.

The restoration of a facility such as a building and its equipment is defined such that the damaged facility is restored to the same state it was in before the tsunami. Since the damage state affects the expense and restoration time, the damage state $(D S)$ is classified into five categories ranging from A (no damage) to $\mathrm{E}$ (severe damage). When the probability of the damage state of a facility under a given tsunami intensity level and the function of the conditional restoration under the damage state of a facility are given, the restoration rate of facility under a given tsunami intensity level is obtained by

$$
R_{F n}(t \mid x)=\sum_{D S=1}^{5} R_{F n}(t \mid D S) P_{F n}(D S \mid x)
$$

where $R_{F n}(t \mid x)$ denotes the restoration rate for the facility $F_{n}$ at time $t$ in days for a given tsunami intensity level $x, R_{F n}(t \mid D S)$ denotes the conditional restoration rate for the facility $F_{n}$ at time $t$ in days for a given damage state $D S$, and $P_{F n}(D S \mid x)$ denotes the probability of a damage state $D S$ of the facility $F_{n}$ for a given tsunami intensity $x$

The DS of a facility is classified into five discrete categories. Each of these categories corresponds to a damage rate of the facility, $y$, which is treated as a random variable with a corresponding probability distribution, $f(y \mid x)$, at every tsunami intensity level, $x$, as shown in Fig. 5. Each DS has a representative value of damage rate as listed in Table 1, and the probability of the damage state is expressed by section integral calculus of the distribution's lowest damage rate $y_{1}$ to the highest damage rate $y_{2}$ when given the damage rate distribution $f(y \mid x)$ as follows. 


\begin{tabular}{ccc}
\hline Damage state $D S$ & $\begin{array}{c}\text { Central value of damage } \\
\text { state } k_{D S}\end{array}$ & $\begin{array}{c}\text { Interval of damage rate } \\
\left(y_{1} \leq y<y_{2}\right) \text { in } \%\end{array}$ \\
\hline \hline A & 1.00 & $87.5 \leq y \leq 100$ \\
B & 0.75 & $62.5 \leq y<87.5$ \\
C & 0.50 & $37.5 \leq y<62.5$ \\
D & 0.25 & $12.5 \leq y<37.5$ \\
E & 0.00 & $0 \leq y<12.5$ \\
\hline
\end{tabular}

Table 1. Definition of damage state $D S$

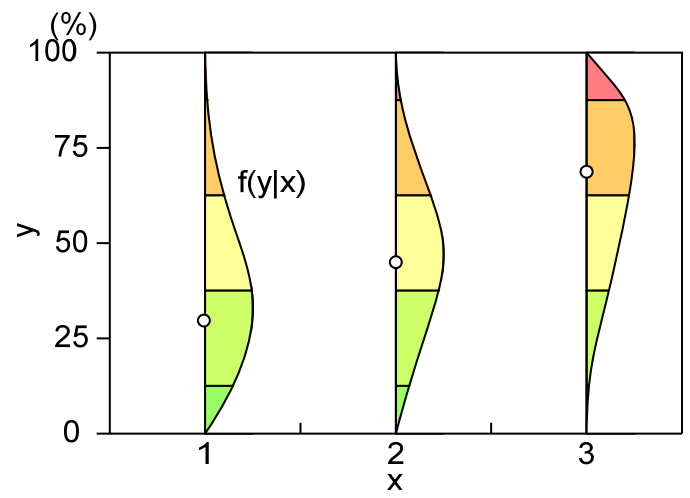

Fig. 5. Schematic model of tsunami intensity level $x$ and damage rate, $y$

$$
P_{F n}(D S \mid x)=\int_{y 1}^{y 2} f_{F n}(y \mid x) d y
$$

A distribution model of the damage rate is assumed as the beta distribution between 0 and 1 as follows. Its parameters, $q$ and $r$, are estimated by statistical inference.

$$
f_{F n}(y \mid x)=\frac{y^{q-1}(1-y)^{r-1}}{B(q, r)} ; 0 \leq y \leq 1
$$

Regarding the restoration rate model, the concept is based on the method by Nojima and Sugito (2005). The conditional restoration ratio of the damage state for a facility, $R_{F n}(t \mid D S)$, can be expressed by the central damage rate of the damage state, $k_{D S}$, and the cumulative density function of the conditional restoration rate, $r_{F n}(t \mid D S)$, as shown in Eq. (4).

$$
R_{F n}(t \mid D S)=1-k_{D S}+k_{D S} \int_{0}^{t} r_{F n}(\tau \mid D S) d \tau
$$

A probability density distribution of restoration rate, $r_{F n}(t \mid D S)$, is assumed as the gamma distribution as shown in Eq. (5). Its parameters, $v$ and $k$, are also estimated by statistical inference.

$$
r_{F n}(t \mid D S)=\frac{v(v t)^{k-1} e^{-v t}}{\Gamma(k)} ; t \geq 0
$$


Three kinds of lifelines, all of which are related to business activity, are considered: water supply, electric power, and telecommunication. Contrary to the business facility, the lifeline facility covers a widespread area, and therefore, the damage to the lifeline facility is also widespread. If the service to end users of a lifeline is functioning even after a natural disaster, the lifeline is not an obstacle for business recovery. Hence lifeline damage for business should be taken into account not based on its physical damage but rather on its functional damage. This study thus considers the functionality of lifelines on the user side. The concept of an evaluation model of lifeline restoration is similar to that of the business facilities. Here, the damage state of lifeline systems is categorized into two states regardless of whether the lifeline is functioning. When the lifeline system is functional, the representative value $k_{D S}$ of the $D S$ becomes 0 , and the state of restoration rate $R_{L n}(t \mid D S, D S=$ functional $)$ becomes 1 . In contrast, when the lifeline is not functional, $k_{D S}$ becomes 1 , and $R_{L n}(t \mid D S, D S=$ not functional $)$ gives the cumulative density distribution of the conditional restoration rate.

\subsection{Application of post-tsunami restoration model 3.4.1 Facility restoration}

The proposed restoration model was applied to estimate the restoration curves according to the tsunami intensity based on the collected data in southern Sri Lanka. First of all, damage state parameters and restoration rate parameters were calculated based on the equations presented above. The restoration process and resistance to tsunami force vary depending on the type of building, the conditions of the facilities, and so on. In the present study, we do not have enough responses to analyze these factors separately. All the buildings for different industries are assumed to have the same resistance and are arranged without distinguishing between industrial classifications. Only answers from the fishing industry, which is dependent to fishing boats and is quite different from the others, were removed from this analysis.

Tables 2 and 3 list the mean and variance of the observed building and equipment damage rate, $y$, and beta distribution parameters for the different levels of tsunami intensity by the method of moment. If the tsunami level is 0 (no inundation), it can be concluded that there was no physical damage to the building and facilities. In addition, as the number of responders of tsunami intensity levels 2 and 3 is limited, their number is modified by adding weighted responders from the previous and the next intensity level.

As shown by the results in Tables 2 and 3, the mean damage rate increases according to tsunami intensity level, and the variance of levels 2 and 3 shows high values. Thus, the probability distribution function of damage rate has two peaks between borders.

\begin{tabular}{cccccc}
\hline$x$ & $N$ & $E(y)$ & Var $(y)$ & \multicolumn{2}{c}{ B-dstrb. parameter } \\
\hline \hline 1 & 3 & 0.167 & 0.021 & 0.94 & $r$ \\
2 & $8^{*}$ & 0.560 & 0.151 & 0.35 & 0.28 \\
3 & $14^{*}$ & 0.669 & 0.119 & 0.57 & 0.28 \\
4 & 15 & 0.783 & 0.115 & 0.37 & 0.10 \\
\hline
\end{tabular}

Table 2. Parameters of building damage rate, $y(\%)$, due to the tsunami intensity level, $x$ 


\begin{tabular}{cccccc}
\hline$x$ & $N$ & $E(y)$ & $\operatorname{Var}(y)$ & \multicolumn{2}{c}{ B-dstrb. parameter } \\
\hline \hline 1 & 3 & 0.167 & 0.083 & 0.11 & 0.56 \\
2 & $6^{*}$ & 0.563 & 0.235 & 0.03 & 0.02 \\
3 & $14^{*}$ & 0.769 & 0.115 & 0.42 & 0.13 \\
4 & 17 & 0.912 & 0.031 & 1.47 & 0.14 \\
\hline
\end{tabular}

Table 3. Parameters of facility damage rate, $y(\%)$, due to the tsunami intensity level, $x$

Tables 4 and 5 list the probabilities of the building and equipment damage state using the beta distribution's parameters. For the damage states A and B, the probability increases as the tsunami intensity level becomes large. Comparing probabilities between building and equipment, high probability appears at the severe damage state in the equipment rather than the building.

\begin{tabular}{cccccc}
\hline & \multicolumn{5}{c}{ Tsunami intensity level $x$ (inundation height $h(\mathrm{~m})$ ) } \\
DS & 0 & 1 & 2 & 3 & 4 \\
& $h=0$ & $0<h \leqq 1$ & $1<h \leqq 2$ & $2<h \leqq 3$ & $h>3$ \\
\hline \hline A & $0 \%$ & $0 \%$ & $36 \%$ & $44 \%$ & $67 \%$ \\
B & $0 \%$ & $1 \%$ & $15 \%$ & $18 \%$ & $9 \%$ \\
C & $0 \%$ & $9 \%$ & $11 \%$ & $13 \%$ & $6 \%$ \\
D & $0 \%$ & $41 \%$ & $14 \%$ & $13 \%$ & $7 \%$ \\
E & $100 \%$ & $49 \%$ & $24 \%$ & $12 \%$ & $11 \%$ \\
\hline
\end{tabular}

Table 4. Probability of building damage state, $P_{F n}(D S \mid x)$

\begin{tabular}{cccccc}
\hline & \multicolumn{5}{c}{ Tsunami intensity level $x$ (inundation height $h(\mathrm{~m})$ ) } \\
DS & 0 & 1 & 2 & 3 & 4 \\
& $h=0$ & $0<h \leqq 1$ & $1<h \leqq 2$ & $2<h \leqq 3$ & $h>3$ \\
\hline \hline A & $0 \%$ & $6 \%$ & $54 \%$ & $64 \%$ & $80 \%$ \\
B & $0 \%$ & $6 \%$ & $2 \%$ & $11 \%$ & $12 \%$ \\
C & $0 \%$ & $6 \%$ & $1 \%$ & $7 \%$ & $5 \%$ \\
D & $0 \%$ & $10 \%$ & $2 \%$ & $8 \%$ & $3 \%$ \\
E & $100 \%$ & $71 \%$ & $42 \%$ & $11 \%$ & $1 \%$ \\
\hline
\end{tabular}

Table 5. Probability of equipment damage state, $P_{F n}(D S \mid x)$

Then the parameters of the probability density distribution of the restoration rate, $r_{F n}(t \mid D S)$, are estimated in every damage state of building and equipment. Even 9 months after the tsunami (at the end of September, 2005), most fisheries were under the process of restoration or had not been restored yet. Thus responders from the fishing industry were removed from the analyses. A total of 5 out of 29 responders (building/equipment or both) had not been recovered at the time of the survey. The government announced that the area within a $100 \mathrm{~m}$ buffer zone from the shore would not be supported. This regulation would 
also hamper a quick restoration. Here, the number of days until restoration completion of the above not restored building/equipments is considered to be 360 days.

In Tables 6 and 7, the parameters of the probability density distribution of restoration rate in the each damage state for buildings and equipment are presented, respectively, using the gamma distribution by the method of moment. The damage state " $D$ " of Table 7 is assigned from relations with recovery days of other damage states because of a lack of records. As the damage state becomes severe, the mean of the restoration days gets longer.

\begin{tabular}{cccccc}
\hline DS & $N$ & $E(t)$ & $\operatorname{Var}(t)$ & \multicolumn{2}{c}{ Gamma- dstrb. parameter } \\
& & & & $k$ & $v$ \\
\hline \hline A & 14 & 204.6 & 11894.1 & 3.52 & 0.0172 \\
B & 3 & 220.0 & 22800.0 & 2.12 & 0.0096 \\
C & 2 & 130.5 & 23980.5 & 0.71 & 0.0054 \\
D & 10 & 54.9 & 4887.0 & 0.62 & 0.0112 \\
\hline
\end{tabular}

Table 6. Parameters of restoration density function of damage states for buildings

\begin{tabular}{cccccc}
\hline \multirow{2}{*}{$D S$} & \multirow{2}{*}{$N$} & $E(t)$ & \multirow{2}{*}{$\operatorname{Var}(t)$} & \multicolumn{2}{c}{ Gamma- dstrb. parameter } \\
& & & & $k$ & $v$ \\
\hline \hline A & 18 & 158.9 & 7607.5 & 3.32 & 0.021 \\
B & 4 & 113.8 & 16156.3 & 0.80 & 0.007 \\
C & 5 & 76.2 & 15702.2 & 0.37 & 0.005 \\
D & 2 & $36.4^{*}$ & $1000.0^{*}$ & 1.32 & 0.036 \\
\hline
\end{tabular}

Table 7. Parameters of restoration density function of damage states for equipment

Furthermore, the conditional restoration rate of each damage state is shown in Figs. 6 and 7. If the building is in damage state " $\mathrm{A}$ " or " $\mathrm{B}$ ", it has a dramatically slow restoration; in contrast, the restoration curve is convex if it is in another damage state. In other words, if the industrial building and equipments were completely destroyed or washed away by the tsunami wave, more time was needed for restoration because of the cost of new construction. Moreover, with regard to the equipment, the damage state A shows a concave restoration process, but other damage states show fast restoration.

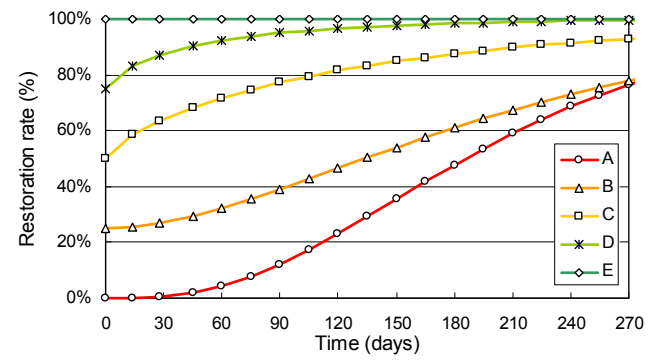

(a) Building damage state, $r_{F n}(t \mid D S)$

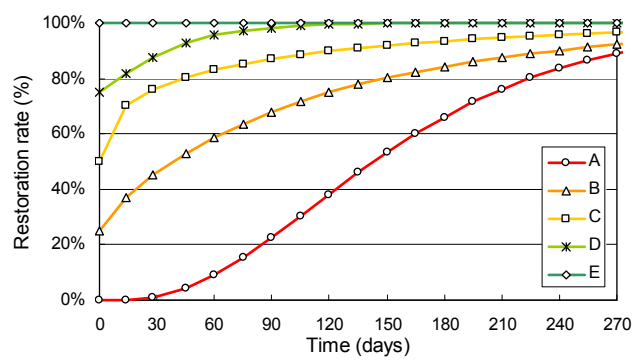

(b) Equipment damage state, $r_{F n}(t \mid D S)$

Fig. 6. Restoration rate of damage state 


\subsubsection{Lifeline restoration}

Here, we estimate the restoration process of lifeline systems such as electricity, water supply, and telecommunication. In this regard, the actual probability of the lifeline damage state and the restoration days indicated by the responders are employed because there is not enough information on the lifeline network system and the inundation area to be analyzed. Furthermore, the number of restoration days for the users is much higher than that of the main network reported by lifeline companies. Fig. 7 shows the supply interruption rate of the lifeline companies due to tsunami intensity level. It shows a 20 to $50 \%$ interruption of lifeline even though the area had not been hit by the tsunami wave. In addition, the electricity and water-supply services stopped completely when the inundation level was more than $2 \mathrm{~m}$. Thus, it can be concluded that the above-ground lifeline facilities such as electric power and water meters are easily destroyed by tsunami waves. The interruption in telecommunication was less than that for other lifelines because of the functioning of mobile phones during and after the tsunami.

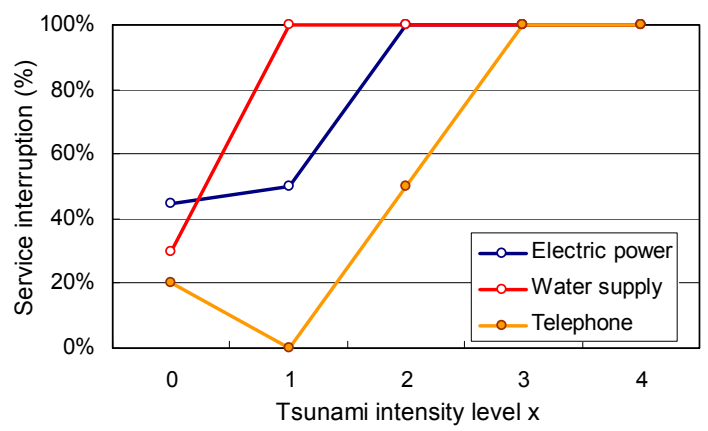

Fig. 7. Lifeline service interruption by tsunami intensity level

Similar to the facilities, the probability density distribution of the restoration rate was estimated using the gamma function by the method of moment as shown in Table 8. We had some responders whose lifeline services had not been recovered at that time. Because the outside buildings were still under construction, it was not possible to install inside facilities. In this study, we have removed those answers from the analyses. The mean number of days for water-supply restoration was 58 days, and that for electric power supply and telecommunication was 39 days. Fig. 8 shows the comparison of the values observed and the proposed model of lifeline services. The proposed model could express the characteristics of observation values appropriately.

\begin{tabular}{cccccc}
\hline Ln & $N$ & $E(t)$ & $\operatorname{Var}(t)$ & \multicolumn{2}{c}{ Gamma- dstrb. parameter } \\
& & & & $k$ & $v$ \\
\hline \hline Water & 18 & 58.3 & 3644.2 & 0.93 & 0.016 \\
Power & 26 & 38.5 & 2512.2 & 0.59 & 0.015 \\
Telecom. & 15 & 38.7 & 1381.1 & 1.08 & 0.028 \\
\hline
\end{tabular}

Table 8. Parameters of the restoration density function of lifeline service 


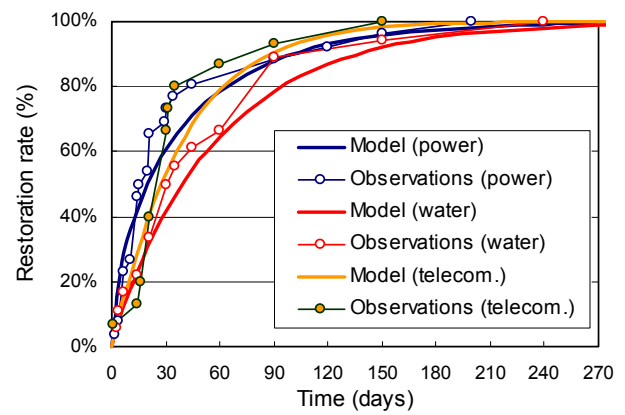

Fig. 8. Restoration curves of lifeline service

\subsubsection{Business base restoration under inundation height}

The restoration curves of business facilities and lifelines under the same tsunami intensity level are compared, as shown in Fig. 9. As can be seen in this figure, business facilities such as building and equipment are restored sooner than the lifelines if the tsunami intensity level is either 1 or 2 . However, business facilities are restored slower than lifelines if the tsunami intensity level is 3 or higher. When the tsunami inundation height is higher than 1 $\mathrm{m}$, the business recovery depends more strongly on the business facilities rather than the lifeline.

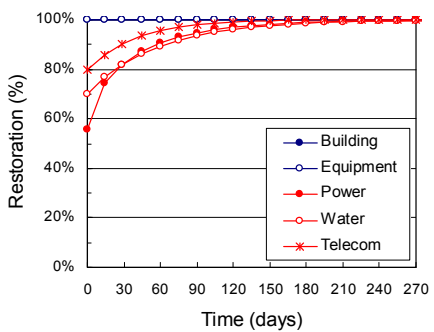

(a) Level 1(no inundation)

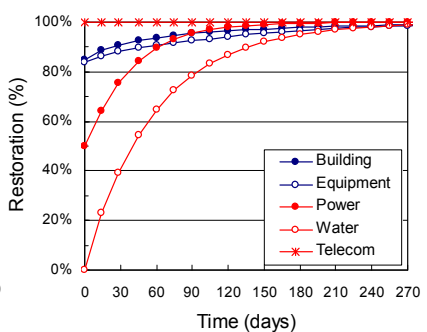

(b) Level $2(h \leq 1(\mathrm{~m}))$

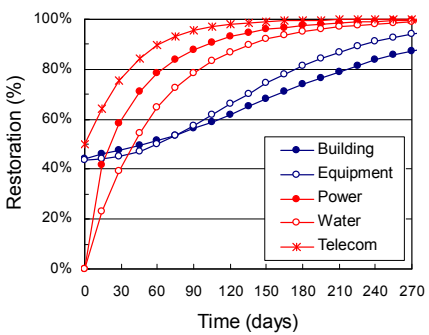

(c) Level $3(1<h \leq 2(\mathrm{~m}))$

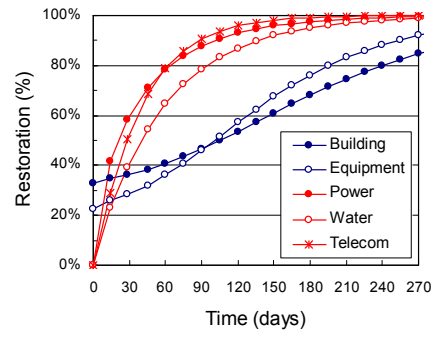

(d) Level $4(2<h \leq 3(\mathrm{~m}))$

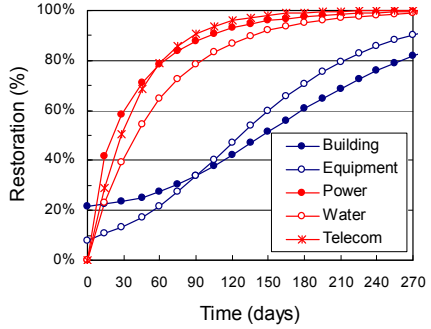

(e) Level $5(h>3(\mathrm{~m}))$

Fig. 9. Restoration curves of business bases by tsunami intensity level 
It should be noted that lifelines are damaged even in places where the tsunami does not reach, as is shown in Fig. 9(a). This is because the lifeline is a system that works in a wide area. Moreover, since the lifeline is managed as a public service, its restoration is relatively rapid. The restoration of buildings and equipment, which are mostly private property, is very slow, especially in the first three month after a disaster, relative to the lifeline.

\subsection{Restoration processes for business bases and entire business}

Fig. 10 shows the temporal change of business base restoration rate for the three selected types of industry (fishing, manufacturing, and tourism). The observed temporal changes of entire business recoveries for each industry are also shown (same as Fig. 3). The entire business recovery is the same as or smaller than the restoration of the business base. For the fishing industry, sales depend strongly on equipment (fishing boat) restoration. While the lifeline is recovered soon in the manufacturing industry, business restoration is connected to facility restoration. For tourism (hotels), both the restorations of the entire business and the business base are almost the same. It is indicated that in the first few months, lifeline services were restarted at a slightly damaged hotel, and an extensively damaged hotel was restored with lifeline repair a few months later. In other words, the hotel industry cannot run without a lifeline service. The results of a comparison of restoration processes show that the influences of the business base on the entire business functionality are different among the industries.

The failure of the lifeline systems affects the residual function of societies in a variety of ways. ATC-13 (Applied Technology Council, 1985) provided a methodology for evaluating the impact of lifeline failures on the loss of function of particular facilities, and they also established an index called the importance factor. Important factors were developed based on the judgment of experts, and they were prescribed for California conditions only. Thus, the importance factors of lifeline systems are examined based on the results of a survey in Sri Lanka, with reference to the methodology of ATC-13.

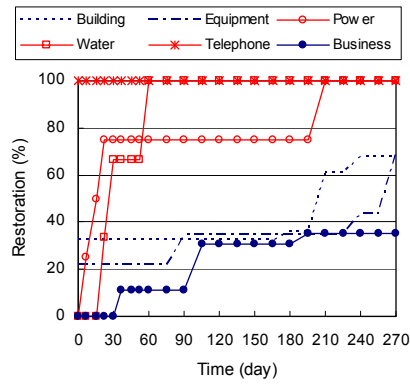

(a) Fishery

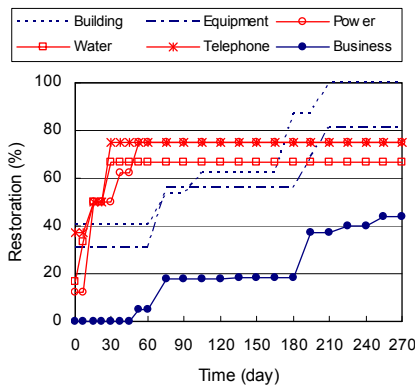

(b) Manufacture (others)

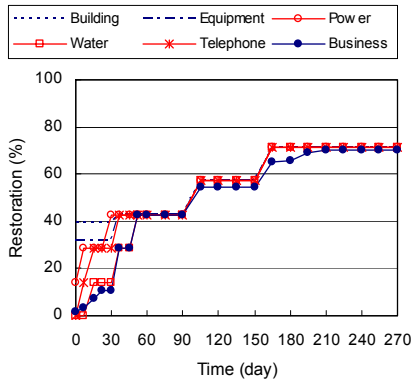

(c) Tourism (hotel)

Fig. 10. Restoration processes of business bases and entire business 
The importance factor examined in this study is only for three lifelines: water supply, electric power, and telecommunications. Each industry will be given three importance factors. The multiple regressions model considering three explanatory variables in terms of functionality of the lifelines is used. Observations of each variable are used from the data by the mean values taken every few weeks for each industry, as in Fig. 3. The results show that the estimated importance factors are mostly close to 1.0, which indicates that lifelines have a severe effect on business activity (Kuwata et al., 2006). In particular, all the factors of financial institutions, hotels, and lifeline businesses are 1.0. These factors are much larger than those in ATC-13. When a business facility and several lifelines lose functionality at the same time, it is considered that the interrelation of business bases increases and the importance factor become large.

\subsection{Remarks on business restoration model}

The evaluation model of restoration curves for the business base was applied from the results of the interview survey of businesses in southern Sri Lanka. When buildings and equipment have extensive damage or are flooded completely, their restoration starts slowly in the first few months. The business restoration depends more strongly on business facility restoration than lifeline restoration if the tsunami inundation is higher than $1 \mathrm{~m}$. The lifeline interruption caused by the tsunami affected business continuity more than in previous studies.

The concept of a restoration model is applicable to those businesses that are flooded by a tsunami. The damage rate and restoration curve estimated in this study is based on the limited number of responses. The parameters shown herein may have to be examined using additional responses.

Although the business recovery seems to be related to several social factors, such as regional policy of disaster recovery, regulation, culture, and psychological issues of customers, this model deals only with the physical aspect of facilities. These social factors should be clarified in future work.

\section{Community-based lifeline reconstruction planning}

Disaster reconstruction planning is generally necessary to make the affected area stronger than it was before the disaster. It provides the opportunity to review the vulnerability of the town to earthquakes and tsunamis, and to create a vision for development between government and community. If the planning vision or procedure fails, the community might not survive. Therefore, it is important for the suffering community to heal and persevere after the disaster. The disaster reconstruction planning discussed herein targets the area affected by the tsunami. Houses collapsed and were swept out by the wave, leaving an area of land with a cleared surface. Drastic town planning is easier to implement in this area rather than an earthquake-affected area, where the damaged houses are unevenly distributed.

Lifeline reconstruction planning follows the land readjustment of town lots. Through the reviews of disaster reconstruction planning at two tsunami-affected areas-Nam Kem village, Thailand and Aonae district, Japan-the implementation procedure between the local government and community is discussed. As part of disaster restoration including readjustment, the lifeline network can be completely renovated and become strong in terms 
of network system, although the general procedure of lifeline restoration after the earthquake is to replace only the broken or leaked pipe with the new pipe and to keep the former system of the pipeline network. Therefore, post-tsunami lifeline reconstruction has a sense of new construction.

\subsection{Town reconstruction planning at Nam Kem village, Thailand}

The tsunami damage to the underground water supply pipeline at Nam Kem village, Thailand was shown above. In addition to the water-supply pipeline, houses also almost collapsed near the coast. To secure the safety of residents and coastal property, the Department of Public Works and Town Planning (hereafter, DPT), Ministry of the Interior, Thailand proposed a town reconstruction plan for Nam Kem village shortly after the tsunami, as shown in Fig. 11. This plan divides the village into four types of land-use areas (public, fishery, living, and monument \& sightseeing), and it provides new roadways, parts of which are suitable evacuation routes. It seems like an ideal land readjustment project from the point of view of land use planning. On the other hand, it would force local fishery residents to move far from the coast.

In fact, the destructive tsunami damage at Nam Kem village had received a lot of attention from domestic and international organizations. They sent much disaster relief and donations to help restore the houses of the victims. This support helped the village to recover earlier. Under military management, permanent houses built in a couple of weeks were provided to those who had lived in the same place as before. Within three months after the tsunami, the affected residents started coming back to their rebuilt houses. This process was so quick that the affected community, local government, and central government, such as DPT, could not participate in the town reconstruction. The community relationships were strong because the residents have lived there for a long time, spanning many generations. They did not accept the changes to their livelihoods and residences based on the DPT town readjustment plan, and they insisted on restoring the village to its pre-tsunami state.

Since the land readjustment planning was accepted in the disaster restoration planning and the house rebuilding was fast, the lifeline recovery in the village was also installed in the same place as before. According to the DPT planning, the cost of the planned water-supply pipeline is estimated by the network map, as shown in Fig. 13 (2). When the repair costs of the damaged pipelines and the construction costs of the planned pipeline are compared, as shown in Fig. 12, the costs are 117 thousand USD and 105 thousand USD, respectively, which are not so different. Similarly, the costs for the electric power line are also not very different from each other. It is observed that the cost for lifeline facilities is not different between the new plan and the repair scenario.

Whether residents move and live in a safer place or remain in the community depends on the communication between the local community and the government. The roadway administrator and lifeline companies may join the discussion, providing information for safer town development. Although they reject the idea of moving, the town designer and infrastructure organization would agree to rebuild better facilities. Three years after the tsunami, most houses were rebuilt within $500 \mathrm{~m}$ from the coast, as before. The population did not increase very much, but water users increased from 300 customers to 600 customers. The vulnerable parts, including the water meter mentioned above, have not improved from the former equipment. The shallow well filled with seawater cannot be restored. 


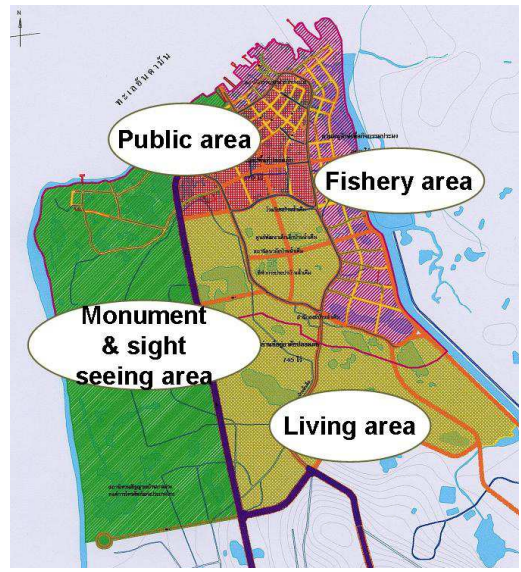

Fig. 11. Nam Kem village reconstruction planning (Source: DPT, Thailand)

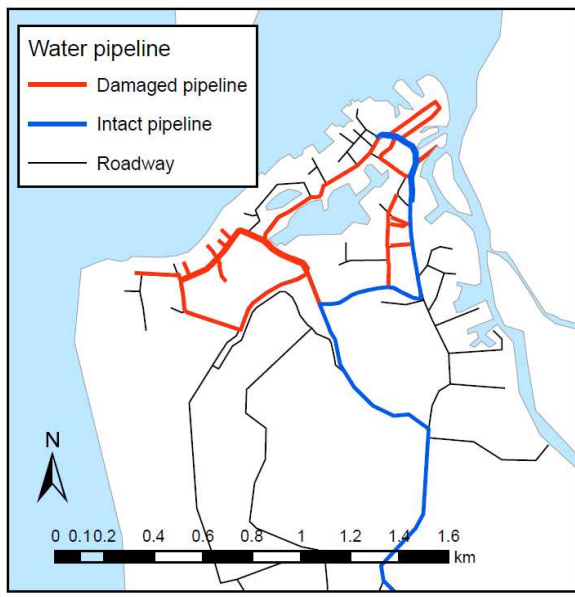

(1) Current pipeline after tsunami

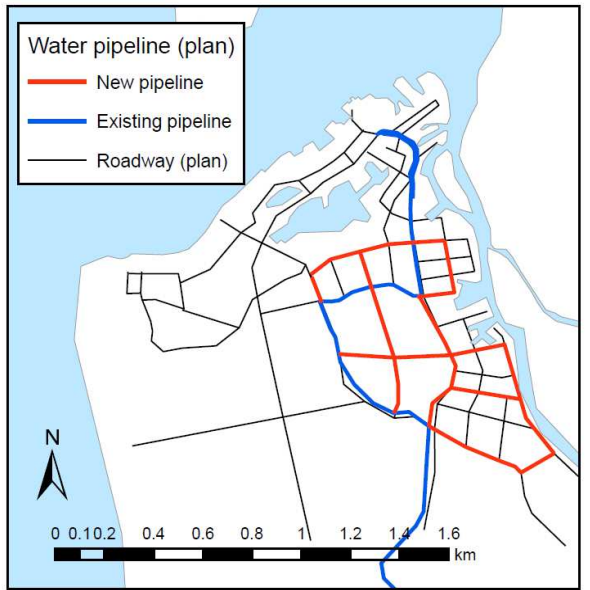

(2) Planned pipeline based on DPT planning

Fig. 12. Nam Kem village reconstruction planning (DPT, Thailand)

\subsection{Town reconstruction planning of Aonae district, Okushiri}

The Hokkaido southwest-off earthquake (M7.8) that hit Okushiri Island at 22:17 (local time) on July 12, 1993 caused extensive damage and resulted in 172 deaths and 27 missing people; the population of the island was 3700. Aonae district at the south cape of the island, where fishing was the main industry, was the most severely affected part of the island. Tsunami and post-earthquake fires were the main causes of death and destruction. In total, 107 people were killed or missing in Aonae district alone. Those who had escaped to the hill survived. In inundated or burned areas, very few wooden houses remained. Incidentally, half of the direct damage from the tsunami was inflicted on infrastructure and port facilities. 
The victims evacuated the shelter after one and a half months, and they stayed in temporary houses for three and a half years, with 900 people in total. Okushiri town established a disaster restoration office three month after the tsunami and aimed to complete the disaster restoration planning in five years. Its disaster reconstruction planning was supported by the national government and the Hokkaido prefecture. The reconstruction project that was presented to the Aonae district consisted of four parts: the fishery village environmental renovation project, the roadway reconstruction project, the disaster recovery project (construction of a tide wall), and the group relocation project for disaster prevention. The tide wall, which was built to a height of $6 \mathrm{~m}$ after the tsunami in 1983, was reinforced with a height of 5 additional meters. The wall height of $11 \mathrm{~m}$ is the same as the wave height of the last tsunami. The fishery village environmental renovation project was responsible for the reclaimed land development behind the high-raised wall. New roadways, water supply, and waste water drains were constructed over the reclaimed land, as shown in Fig. 13. When constructing the reclaimed land, the local government bought all the lots from the residents and readjusted the roadway and the lots. After the lot readjustment, residents bought land from the government. This process requires land renovation for disaster prevention, financial contribution from the local government, financial support from the national government, and the patience of the residents during reconstruction. In parallel to the land development at the coastal area, the group relocation project led the victims (except the fishery people) to live on the hill, as shown in Fig. 14.

Based on the reclaimed land development and new roadway construction, the water-supply pipeline used before was left under the surface before the tsunami, and the new pipeline was constructed over it, as shown in Fig. 15. A polyvinyl chloride pipe (PVC) was adopted in the reconstruction work in spite of the ductile iron pipe (DIP), which was used before the tsunami. As shown in the plan of pipeline networks in Fig. 12, the pipeline in Aonae district was completely reconstructed. In contrast to the previous pipeline, the new pipeline draws streamline.

The completion of reconstruction was declared in Okushiri-Island in March, 1998, 4.5 years after the disaster. Houses and infrastructure reconstruction took a long time. Incidentally, the fishery residents could live in the coastal area under safer condition.

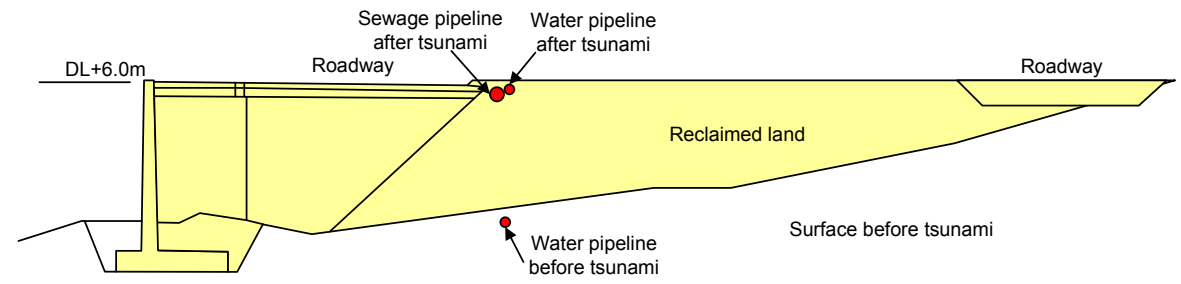

Fig. 13. High-raised tidal wall and reclaimed land development at Aonae district

\subsection{Comparison of town reconstruction planning between two districts}

In Aonae district, the victims were evacuated to shelters at first and then moved to temporary houses for about three years. They were finally settled in permanent houses on reclaimed land. It took such a long time for Aonae district to complete reconstruction because the residents and administrative people worked together to put in place measures that would safeguard them against future large earthquakes and tsunamis. On the other 


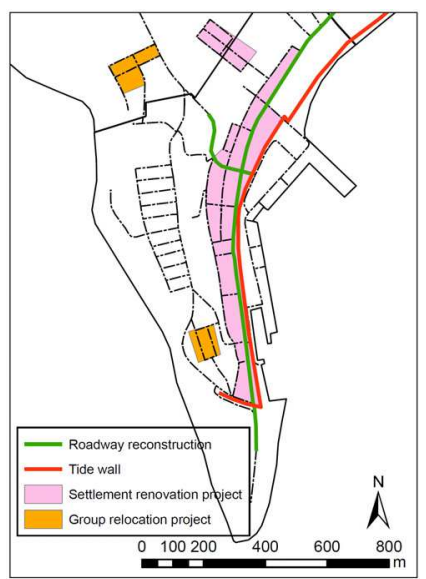

Fig. 14. Disaster reconstruction projects of Aonae district

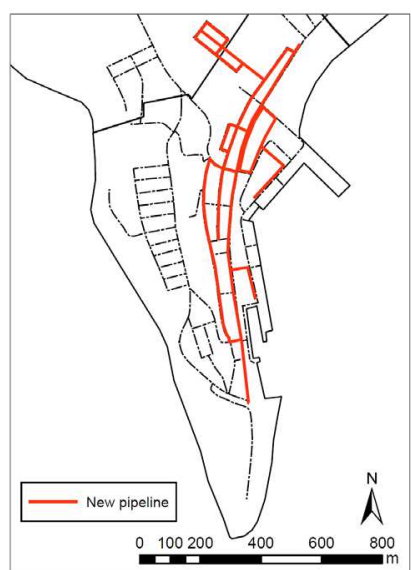

(a) New pipeline (PVC)

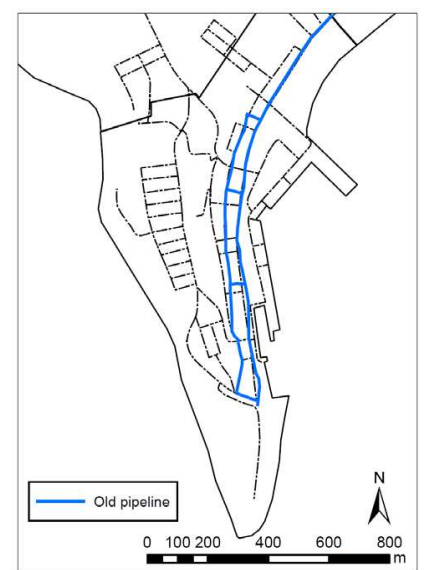

(b) Old pipeline (DCIP)

Fig. 15. Water supply pipeline networks of Aonae district before and after tsunami, underlying on the new roadway

hand, the victims in Nam Kem village needed only three months to move from the temporary shelter to permanent houses because they wanted to rebuild the village as before. The reconstruction in Nam Kem village was focused on going back to the previous state before the tsunami without any improvement of facilities in terms of seismic safety.

Infrastructure, including lifeline facilities, cannot be reconstructed in a short amount of time. Extensive discussions between roadway authorities and other lifeline companies are required to develop a detailed disaster reconstruction plan. Of course, the residents' opinions should be reflected in the plan to maintain the original community. The disaster reconstruction concept in Japan seeks to give more priority to community opinions, even if it takes a long time to complete the reconstruction. For instance, the temporary houses were closed five years after the Kobe earthquake disaster in 1995. The tsunami-affected 
community in Nam Kem village did not have the opportunity to have detailed discussions with the government, and they wanted to retain their traditional lifestyle.

In the reconstruction process, the reconstruction speed, environmental condition after the tsunami, financial support of the government, organization acting as the interface between the government and the community, and traditional and cultural living style are closely related. From the point of view of lifeline reconstruction, it is also important to foster a close relationship among the local government, lifeline companies, and the community and to establish a strong foundation for people-to-people links in order to prepare for an emergency.

After the 2004 Indian Ocean earthquake and tsunami, many villages and towns in Indonesia faced many problems during the reconstruction processes. A lifeline reconstruction process considering community-based planning had not been reviewed in detail so far. This kind of study would be necessary for an effective lifeline reconstruction strategy.

\section{Residential awareness of water use after tsunami}

In suffered area from the 2004 tsunami, residents had mostly used domestic water from shallow well. The domestic water became unavailable after covered with salty water. The salt damage to the shallow well seems to affect residential life quality for a long time. The water-supply system in Banda Aceh, Indonesia was reconstructed and the residents changed their water-supply from shallow wells to a pipeline network. In this section, an analysis on the lifeline reconstruction and its long-term effects, with the focus on residential awareness of water use before and after the tsunami is considered.

\subsection{Reconstruction of water supply system in Banda Aceh}

Banda Aceh is the nearest big city from the epicenter and was suffered severely from the 2004 tsunami. Worldwide institutions helped its reconstruction projects. One of them is the water supply system of Perusahaan Daerah Air Minum (PDAM, meaning provincial drinking water supply authority). The water purification plant of PDAM located at about 10 $\mathrm{km}$ far from coast was fortunately not flooded by the tsunami but had physical damage to facility due to seismic ground motion. Switzerland government supported rehabilitation on of water purification plant, whereas Japan government planned and installed the watersupply pipeline network of $198 \mathrm{~km}$. The repaired purification pant enables to make water for 50,000 customers. By October in 2010 (almost 6 years after the tsunami) the PDAM supplies water to 32,000 customers and is extending service for additional 8,000 customers, who can use PDAM water with no charge until completion of pipeline and other accessories installs. Population of Banda Aceh increased from 170 thousands to 220 thousand with moving people from tsunami-suffered suburb. The water-supply system user also increased from the 2004 tsunami. In Banda Aceh the PDAM user was large comparing the other cities so that underground water is naturally in high level and contains salt.

\section{$\mathbf{5 . 2}$ Interview survey on residential awareness of water use after tsunami}

Interview survey on residential awareness of water use before and after the tsunami was carried out at four districts in Banda Aceh in the beginning of October, 2010. The interview was held at resident's home one by one through Indonesian language and the questionnaire sheet was collected at once. The questions are about water use at home, residential satisfaction rating on water quality and stability, emergency use and so on, and suspension 
limit of water-supply service during a disaster. Fig. 16 shows the interview districts of Banda Aceh, and Table 9 lists the details of responses in each district. 143 answers were obtained as a whole. District A is resettlement house district donated by the Tsuchi religious body, in which all the residents moved from the tsunami-suffered area in and outside Banda Aceh as shown in Fig. 17. The water-supply system was installed at the same time of house construction after the tsunami. Districts B, C and D were suffered from the tsunami by different damage level. With regards of inundation damage report, Districts $\mathrm{C}$, Kuta Raja and D, Meuraxa had inundation and more than $50 \%$ of houses damage, and District B, Syiah Kuara had inundation and less than $50 \%$ of house damage. $80 \%$ of residents live before the tsunami in District B, whereas half of residents moved from the other districts or the suburbs in Districts C and D.

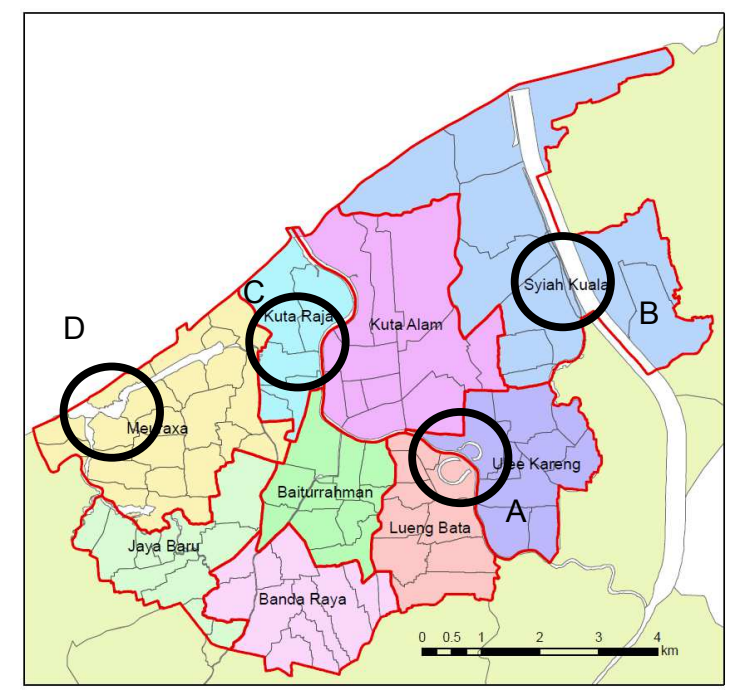

Fig. 16. Location of interview survey district in Banda Aceh

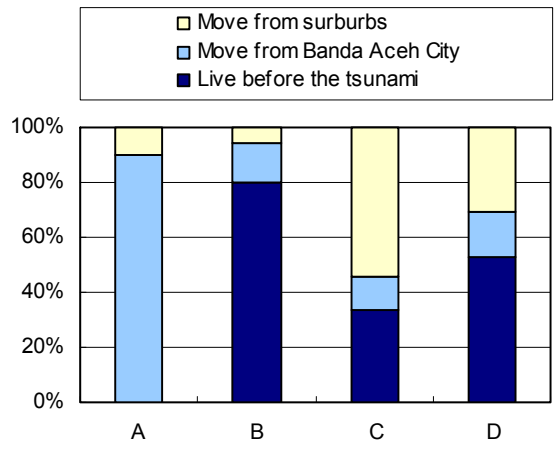

Fig. 17. Location of answers at the 2004 tsunami 


\begin{tabular}{cccl}
\hline District ID. & Name & Responses & Remarks (the 2004 tsunami damage) \\
\hline A & Tsuchi & 39 & Resettlement houses \\
B & Syiah Kuara & 35 & Inland area (moderate damage) \\
C & Kuta Raja & 33 & Riverside area (destructive damage) \\
D & Meuraxa & 36 & Seaside area (destructive damage) \\
\hline Subtotal & & 143 & \\
\hline
\end{tabular}

Table 9. Responses of interview survey on water use after tsunami

The number of answers are not enough statistically, but the rate of PDAM customers in each district as shown in Fig. 18(a) is confirmed to be similar to the statistics of customer number by the PDAM. In resettlement district, A, residents uses 100\% PDAM water-supply, and 70 to $80 \%$ of residents do in the other districts. The PDAM customers without charge in Districts $C$ and D are those live in the area under pipeline construction. Those who do not use the PDAM water use domestic water from shallow well. As a whole, $20 \%$ does not use the PDAM water, 50 \% uses both the PDAM water and domestic water as shown in Fig.18(b) Well user increases in inland Districts A and B.

Among the PDAM users, 10 to $50 \%$ drinks the water after boiling as shown in Fig.19(a). The severely suffered districts, $C$ and D, indicates low rate of drinking customer. Less $10 \%$ drinks domestic water after boiling as shown in Fig.19(b). Water use in Indonesia is

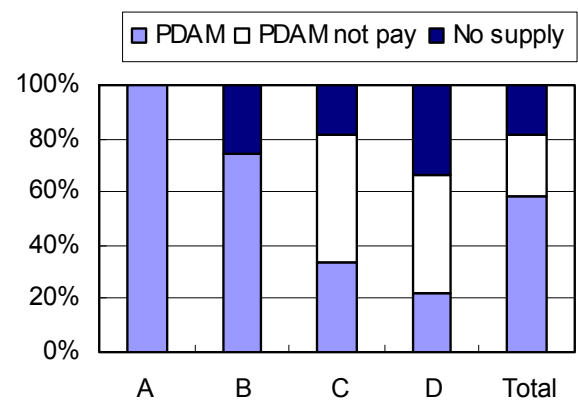

(a) Rate of PDAM customer

Fig. 18. Water use in Banda Aceh

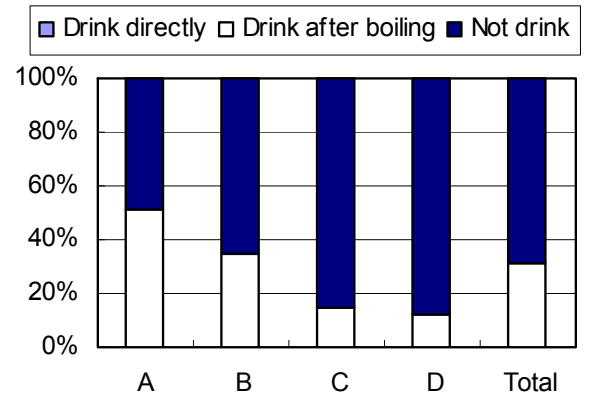

(a) PDAM water

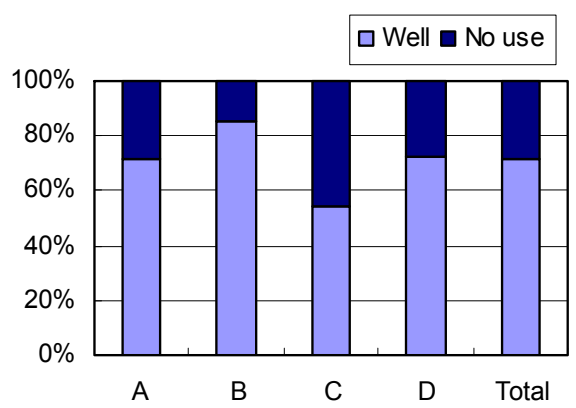

(b) Rate of PDAM customer

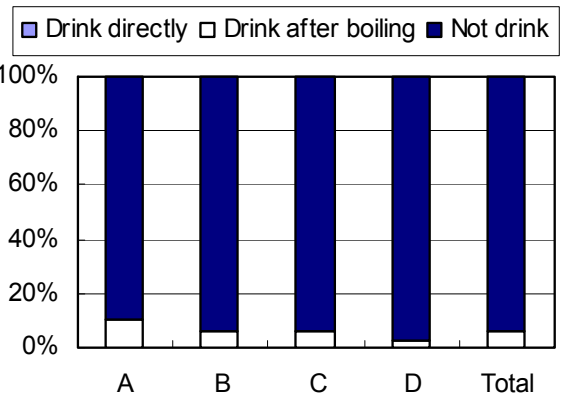

(b) Domestic well water

Fig. 19. Water use for drinking 


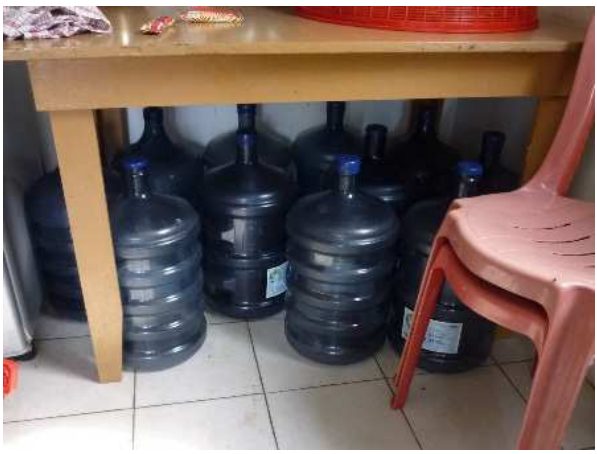

Photo 7. Drinking gallon-size bottle water

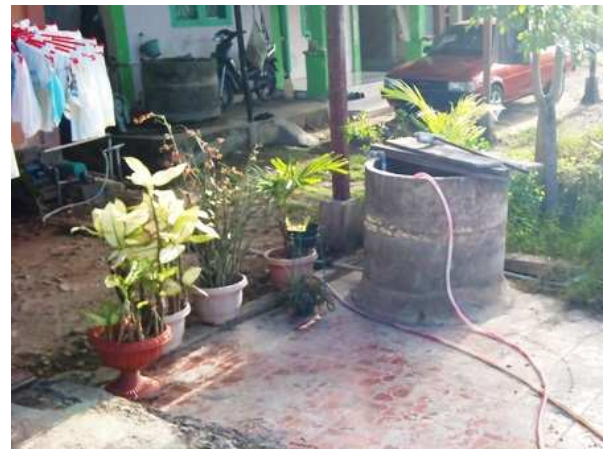

Photo 8. Shallow well in front of house

generally drinking from Gallon-sized bottle water (Photo 7) and living from PDAM water or domestic water (Photo 8). Indonesian residents rarely drink the pipe-water directly.

The residential awareness on water use is examined considering disaster experience and difference between pipe-supply water and domestic water. Here, the residential satisfaction was asked in terms of water quality, water supply stability, emergency stability and water cost by 5 satisfaction options; (1) satisfy very much (2) satisfy (3) reasonable (4) dissatisfy a little and (5) dissatisfy. The response gives grating points from 5 (satisfy very much) to 1 (dissatisfy) for each option. Means of grating point for satisfaction was analyzed by one-way analysis of variance between three groups. Group I is the residents who use the PDAM water before and after the tsunami. Group II is those who started using the PDAM water after the tsunami. Group III is those who have not used the PDAM water. The grating point by Groups I and II is given about the PDAM water, and that by Group III is about the domestic water. Table 10 summarizes the variance analysis results for four questions.

\begin{tabular}{|c|c|c|c|c|c|}
\hline Group & N & $\mu$ & $\sigma^{2}$ & \multicolumn{2}{|l|}{ Test statics } \\
\hline I & 45 & 3.78 & 0.27 & 0.78 & \\
\hline II & 71 & 3.69 & 0.39 & & $5.60^{*}$ \\
\hline III & 27 & 2.78 & 0.95 & $5.42^{*}$ & \\
\hline
\end{tabular}

(a) Variance analysis on water quality. P value $5.67 \times 10^{-9}$ (Significant)

\begin{tabular}{|c|c|c|c|c|c|}
\hline Group & $N$ & $\mu$ & $\sigma^{2}$ & Test statics & \\
\hline I & 45 & 2.13 & 1.53 & $3.08^{*}$ & \\
\hline II & 71 & 2.76 & 0.87 & & 0.18 \\
\hline III & 27 & 2.19 & 0.93 & $2.68^{*}$ & \\
\hline
\end{tabular}

(c) Variance analysis on emergency supply. $\mathrm{P}$ value $2.90 \times 10^{-2}$ (Significant)

\begin{tabular}{lrlll}
\hline Group & \multicolumn{1}{l}{$N$} & $\mu$ & $\sigma^{2}$ & \multicolumn{2}{c}{ Test statics } \\
\hline \hline I & 45 & 2.56 & $1.16 \square^{1.75}$ \\
II & 71 & 2.92 & $1.14 \square$ \\
III & 27 & 3.67 & 0.69 & ${ }_{3.26^{*}}$ \\
\hline
\end{tabular}

(b) Variance analysis on supply stability. P value $9.79 \times 10^{-5}$ (Significant)

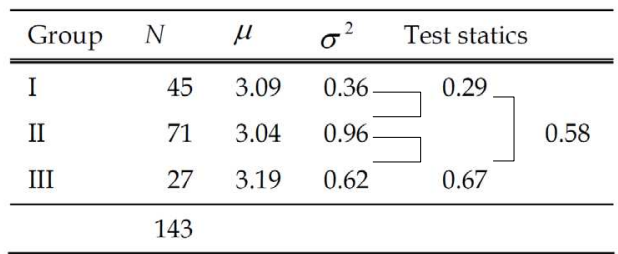

(d) Variance analysis on water cost. P value $7.52 \times 10^{-1}$ (Non significant)

Table 10. Variance analysis on residential awareness on water use. Group I: PDAM customer before the tsunami, Gtoup II: PDAM customer after the tsunami, and Group III: Shallow well usr. * indicates significant diference between two groups (significant level 1\%) 
The mean of grating point between the PDAM user (Groups I and II) and the domestic well user (Group III) differs significantly on water quality and supply stability. The PDAM users satisfy water qualities by around 3.7 grating point, but supply stability by 2.56 to 2.92 grating point. Significant difference between PDAM users staring before and after the tsunami can not be seen. During the interview, the responder pointed out the water for washing clothes. Since the domestic water contains salt rather than before, even 6 years after the tsunami, they use it by the PDAM water or the water filtered by house strainer. The residents who do not satisfy the supply satiability replied that they cannot receive adequate water volume in day time and they install house pump at home and take water. The number of house pump seen in the interview survey is not small. These uncontrolled water pressures may provoke malfuctiionality of whole water supply system.

For the emergency supply stability after disasters, there is significant difference between groups. Those who continue the same water use before the tsunami (Groups I and III) give 2.1 grating points, while the new PDAM user gives 2.76. The new PDAM user is thought to be evacuated people to Banda Aceh city. Emergency water delivery by tanks and expanding new pipeline install by the PDAM may contribute high grating to residential satisfaction.

Water charge is not much effective factor to identify residential awareness in terms of water use and disaster experience as shown in Table 10 (d). By the way, the reason why $100 \%$ of residents do not contract the PDAM water seems to be financial issue. Fig. 20 shows relation between the rate of water cost per income and the residential satisfaction on water charge for PDAM water users. Income rating is classified into 7 classes as shown in Figure. Water cost indicates the PDAM water charge and gallon-sized water bottle purchasing cost per month. The residential satisfaction on water charge is the rate of those who think water charge as inexpensive and half of those who think as reasonable to the all answers, when asked for the water charge in options; expensive, reasonable, and inexpensive. As it can be seen, the residential satisfaction on water charge increases as income increases. A half of residents having over 1.25 million Indonesian Rupiah satisfy the water charge from the PDAM. Their PDAM water charge is less than $10 \%$ of income. When the PDAM water charge increases more than $10 \%$, it interferes with their daily lives. When compared the amount of the PDAM water use, there is little difference of the personal daily water demand in each income class. The life style related to water demand does not differ by the income and the satisfaction depends on the incomes.

It should be noted that the water charge from the PDAM water is almost same as the bottle purchasing cost. The responders buy a monthly average of 11.7 gallon-sized water bottle. One bottle (about 3.785 liter) costs about 5,000 Rupiah and the bottle water costs 1,321 Rupiah per liter. Meanwhile the PDAM water costs about 3 Rupiah per liter. If the PDAM can obtain residents satisfaction on the water quality and residents can drink it even after boiling, the whole residential water charge decreases less than $10 \%$ and the residents also satisfy the water charge. It should be discussed that how much the pipeline network completion for better water quality at the customer side can be invested considering the water charge. These assessments of water pipeline install would be necessary for future work.

In Banda Aceh City the water supply pipeline network install is almost completed. There are many small cities and town around the coast of Sumatra Island, in which the tsunami wave was covered by the 2004 tsunami but the water supply system is not installed yet. Even they do not drink domestic water directly, the salty underground water affects on living use water for long time. The water pipeline network, which may damage by the earthquake and tsunami, would be necessary as reconstruction works to these coastal areas. 


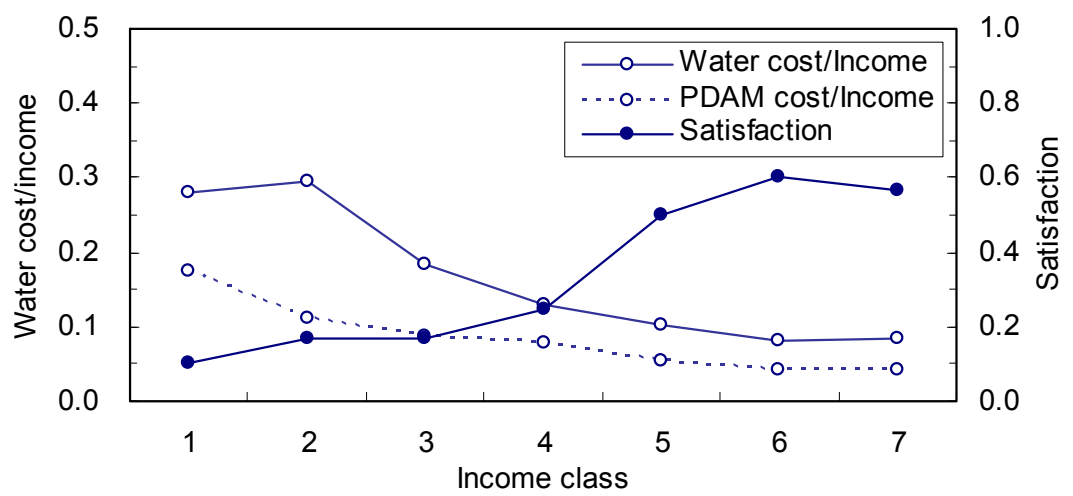

Fig. 20. Water cost rate to income versus water satisfaction regards to monthly income class. Income class 1: < 350,000 IDR, 2: 350,000 - 500,000 IDR, 3: 500,000 - 750,000 IDR, 4: 750,000 1,000,000, 5: 1,000,000 - 1,250,000, 5: 1,250,000 - 1,500,000 IDR, 6: >1,500,000 IDR. IDR=Indonesian Rupiah (1,000 IDR = 0.12 USD =9.4 JPY, 2011)

\section{Conclusions}

This chapter discussed the lifeline restoration and reconstruction after the tsunami, especially focusing on the 2004 Indian Ocean earthquake and tsunami. Followings can be summarized.

- The business restoration depends more strongly on business facility restoration than lifeline restoration if the tsunami inundation is higher than $1 \mathrm{~m}$. The lifeline interruption caused by the tsunami affected business continuity more than in previous studies.

- In the reconstruction process, the reconstruction speed, environmental condition after the tsunami, financial support of the government, organization acting as the interface between the government and the community, and traditional and cultural living style are closely related. From the point of view of lifeline reconstruction, it is also important to foster a close relationship among the local government, lifeline companies, and the community and to establish a strong foundation for people-to-people links in order to prepare for an emergency.

- The salty underground water affects on living use water for long time. The water supply from the pipeline gives high satisfaction to water quality. The pipeline network construction is important to the suffered people.

In the writing of the chapter, east Japan was hit by strong seismic motion and covered with huge tsunami. Many civilized areas changed catastrophic ruins. What we learned from Indonesia, Thailand and Sri Lanka introduced herein may be not applicable directly to Japan, because of different living environment and water use, but founding in business recovery and reconstruction planning would contribute to reconstruct the suffered area.

\section{Acknowledgment}

The author expresses special thanks to Emeritus Professor of Kobe University, Shiro Takada, Mr. Arun Pinta, Department of Disaster Prevention and Mitigation (DDPM), Ministry of Interior, Thailand, and Dr. Nimal P. D. Gamage, Department of Civil Engineering, 
Moratuwa University, Sri Lanka. Interview survey in Banda Aceh was collaborated with Prof. Norio Maki, Kyoto University, Prof. Yuka Karatani, Meijo University, Prof. Muhammad Dirhamsyah, Tsunami Disaster Mitigation Research Center (TDMRC), Syiah Kuara University, Prof. Krishna S Pribadi, Institut Teknologi Bandung.

A part of this study was supported by Science and Technology Research Partnership for Sustainable Development (SATREPS) "Multi-disciplinary Hazard Reduction from Earthquakes and Volcanoes in Indonesia" from Japan Science and Technology Agency (JST), Japan International Cooperation Agency (JICA), State Ministry of Research and Technology of Indonesia (RISTEK) and Indonesian Institute of Science (LIPI).

\section{References}

Ang, A. H.-S. \& Tang, W. H. (2007). Probability Concept in Engineering (2nd edition), John Wiley and Sons, Inc., ISBN-13 978-0-471-72064-5

Applied Technology Council (1985). Earthquake Damage Evaluation Data for California, ATC13, Redwood City

Bang Muang TAO, Phang Nga Province, Thailand (2007). Summary of General Information \& Landscape Information

Department of Disaster Prevention, Cabinet Office, Japan (2005). Business Continuity Guideline, ver.1 http://www.bousai.go.jp/MinkanToShijyou/guideline01.pdf

Department of Public Works and Town Planning, Interior Ministry, Thailand. (2007). Rehabilitation direction of disaster area at Phang Nga Province

Kuwata, Y., Takada, S., Parapayalage, C. D. K (2006). Business impact and restoration model from tsunami disaster, Proceedings of First European Conference on Earthquake Engineering and Seismology, Geneva, Switzerland, Paper No.883.

Nojima, N. \& Sugito, M. (2005). Probabilistic assessment model for post-earthquake serviceability of utility lifelines and its practical application, Safety and Reliability of Engineering Systems and Structures (Proceedings of the 9th International Conference on Structural Safety and Reliability (ICOSSAR 2005)) (on CD-ROM), Rome, pp. 279-287

Okushiri Local Governmental Office. (1996). Record of Okushiri Town during Hokkaido Nansei Oki Earthquake, Hirakawa Press (in Japan)

Phang Nga DDPM. (2005). Earthquake/Tsunami Victims Relief Efforts, Interior Report

PWWA. (2007). Nam Kem Water pipeline network

Shuto, N. (1992). Tsunami Intensity and Damage, Tsunami Engineering Technical Report, 9, pp. 101-136 (in Japanese)

Takada, S., Kuwata, Y. \& Pinta, A. (2010). Damage and reconstruction of lifeline in Phang Nga province, Thailand after the 2004 Indian ocean earthquake and tsunami, Journal of Earthquake and Tsunami, Vol. 4, No. 2, 83-9 


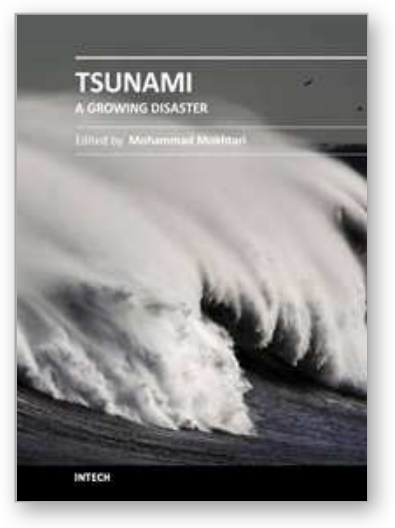

\author{
Tsunami - A Growing Disaster \\ Edited by Prof. Mohammad Mokhtari
}

ISBN 978-953-307-431-3

Hard cover, 232 pages

Publisher InTech

Published online 16, December, 2011

Published in print edition December, 2011

The objective of this multi-disciplinary book is to provide a collection of expert writing on different aspects of pre- and post- tsunami developments and management techniques. It is intended to be distributed within the scientific community and among the decision makers for tsunami risk reduction. The presented chapters have been thoroughly reviewed and accepted for publication. It presents advanced methods for tsunami measurement using Ocean-bottom pressure sensor, kinematic GPS buoy, satellite altimetry, Paleotsunami, lonospheric sounding, early warning system, and scenario based numerical modeling. It continues to present case studies from the Northern Caribbean, Makran region and Tamil Nadu coast in India. Furthermore, classifying tsunamis into local, regional and global, their possible impact on the region and its immediate vicinity is highlighted. It also includes the effects of tsunami hazard on the coastal environment and infrastructure (structures, lifelines, water resources, bridges, dykes, etc.); and finally the need for emergency medical response preparedness and the prevention of psychological consequences of the affected survivors has been discussed.

\title{
How to reference
}

In order to correctly reference this scholarly work, feel free to copy and paste the following:

Yasuko Kuwata (2011). Post-Tsunami Lifeline Restoration and Reconstruction, Tsunami - A Growing Disaster, Prof. Mohammad Mokhtari (Ed.), ISBN: 978-953-307-431-3, InTech, Available from:

http://www.intechopen.com/books/tsunami-a-growing-disaster/post-tsunami-lifeline-restoration-andreconstruction

\section{INTECH}

open science | open minds

\author{
InTech Europe \\ University Campus STeP Ri \\ Slavka Krautzeka 83/A \\ 51000 Rijeka, Croatia \\ Phone: +385 (51) 770447 \\ Fax: +385 (51) 686166 \\ www.intechopen.com
}

\author{
InTech China \\ Unit 405, Office Block, Hotel Equatorial Shanghai \\ No.65, Yan An Road (West), Shanghai, 200040, China \\ 中国上海市延安西路65号上海国际贵都大饭店办公楼405单元 \\ Phone: +86-21-62489820 \\ Fax: +86-21-62489821
}


(C) 2011 The Author(s). Licensee IntechOpen. This is an open access article distributed under the terms of the Creative Commons Attribution 3.0 License, which permits unrestricted use, distribution, and reproduction in any medium, provided the original work is properly cited. 